ESPAÇO TEMÁTICO: ESTADO, AUTORITARISMO E LUTA DE CLASSES

\title{
Usina Hidrelétrica de Belo Monte: lutas sociais e resistência na Amazônia Paraense
}

\author{
Kátia Maria dos Santos Melo \\ https://orcid.org/0000-0001-8151-1467 \\ ${ }^{1}$ Universidade do Estado do Pará, Centro de Ciências Sociais e Educação, Departamento de Filosofia e Ciências Sociais, \\ Belém, PA, Brasil
}

\section{Usina Hidrelétrica de Belo Monte: lutas sociais e resistência na Amazônia Paraense}

Resumo: Este texto analisa as formas organizativas das lutas sociais e resistência na área de influência da Usina Hidrelétrica de Belo Monte, no Pará, diante do projeto energético do governo brasileiro que concebe a Amazônia como produtora de megawatt. Com base no método do materialismo histórico e dialético, foi realizada pesquisa bibliográfica, documental e de campo, mediante entrevistas com lideranças de 16 entidades em três cidades do Pará: Altamira, Vitória do Xingu e Senador José Porfírio. A pesquisa identificou que a resistência é estruturante e se expressa na pluralidade dos grupos sociais que denunciam a política energética brasileira conectada à mundialização capitalista dos territórios, que é materializada pela perda da moradia, violação ao modo de vida de povos originários, barragem de rios, alagamento de comunidades, extinção de espécies aquáticas, plantas e animais, ressurgimento de doenças, extinção de postos de trabalho, deslocamentos compulsórios, aumento da criminalidade e mortes. Danos socioambientais que ameaçam a humanidade genérica.

Palavras-chave: Lutas sociais e Resistências. Movimentos sociais. Usina Hidrelétrica de Belo Monte. Amazônia Paraense.

\section{Belo Monte hydroelectric plant: social movements and resistance on Amazonia}

Abstract: The study analyzes the organizational forms of the social movements and resistances in the influence area of Belo Monte Hydroelectric Plant (UHEBM) before Brazilian government's energetic project, which Amazonia is understood as an energy manufacturer. Based in the dialectical and historical materialism method, it was realized documental and bibliographic researches and interviews with 16 entities in 3 cities of Pará: Altamira, Vitória do Xingu and Senador José Porfírio. The research have identified that the resistance is structured and expresses itself in the plurality of social groups that denounce the Brazilian's energetic policy connected to the capitalist globalization of territories, materialized by the loss of housing, violation of the way of life of the native people, river dam, flooding of communities, extinction of aquatic species, plants and animals, resurgence of diseases, extinction of jobs, compulsory displacements, increase in the crime rate and deaths. Socio-environmental damage that threatens the generic humankind.

Keywords: Social Movements and Resistances. Social Movements. Belo Monte Hydroelectric Plant. Amazonia in Pará.

Recebido em 30.06.2020. Aprovado em 30.08.2020. Revisado em 22.10.2020.

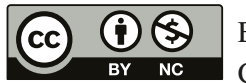

Este é um artigo publicado em acesso aberto (Open Access) sob a licença Creative Commons Attribution NonCommercial, que permite uso, distribuição e reprodução em qualquer meio, sem restrições desde que sem fins comerciais e que o trabalho original seja corretamente citado. 


\section{Introdução}

Este artigo analisa as formas organizativas das lutas sociais e resistência na região de influência da Usina Hidrelétrica de Belo Monte (UHEBM), localizada ao Oeste da Amazônia Paraense, cuja cidade polo é Altamira. A UHEBM foi programada com capacidade instalada para gerar 11.233,1 megawatts (MW), mas em 2019 gerou apenas 3.667 MW para a rede nacional (AGÊNCIA NACIONAL DE ENERGIA ELÉTRICA, 2020), ou seja, aquela que foi planejada para ser a terceira maior hidrelétrica do mundo, financiada com $85 \%$ de recursos públicos do Banco Nacional de Desenvolvimento Econômico e Social (BNDES), por meio de consórcio composto por empresas estatais e privadas, não alcançou $30 \%$ do seu objetivo precípuo.

O modo de produção capitalista, por sua própria natureza, se configura por meio da exploração e do esgotamento dos bens naturais, como as riquezas minerais, o potencial hídrico etc. Essa dinâmica também necessita da exploração da força de trabalho vivo para o desenvolvimento cumulativo desse sistema. Assim sendo, a ampliação da geografia do capital estabelece um percurso que forja o desenvolvimento das infraestruturas física e social do sistema capitalista (HARVEY, 2005). Exemplo desta infraestrutura foi a necessidade do capital de construção da UHEBM, que causou impactos negativos para a vida dos moradores da Região do Xingu.

A pesquisa foi orientada pelo método do materialismo histórico e dialético, considerando as categorias ontológicas de análise da realidade que são apreendidas a partir de sucessivas aproximações da essência do objeto (PAULO NETTO, 2011), que, nesse caso, percorre as relações que expressam as lutas dos movimentos sociais de resistência que dão vida ao objeto. Além da leitura dos documentos sobre a implantação da UHEBM, foi realizada pesquisa de campo nos municípios de Altamira, Vitória do Xingu, Senador José Porfírio, localidades mais próximas da usina, e uma entrevista em Brasília ${ }^{1}$. Foram entrevistados 20 representantes de movimentos sociais de 16 entidades $^{2}$. As entrevistas foram realizadas em dois períodos e anos distintos (novembro de $2014 \mathrm{e}$ janeiro de 2015). Os segmentos entrevistados foram: Associações de moradores e de pescadores; Organizações Não Governamentais (ONGs); lideranças indígenas; representantes de entidades religiosas; sindicatos; setor de comunicação e rádio comunitária.

A pesquisa definiu sete questões norteadoras para investigação da realidade, a saber: (i) organização, articulação e mobilização; (ii) níveis de pressão sofrida no movimento; (iii) parcerias e cooperações estabelecidas; (iv) forma de sustentabilidade financeira; (v) avanços e retrocessos da luta; (vi) as perspectivas e desafios; e (vii) os horizontes das lutas sociais para além de Belo Monte. O texto está estruturado em duas seções, além desta introdução. Na primeira parte são apresentados dados sobre a UHEBM como um elemento da expansão do capital na Amazônia Paraense. Na segunda seção são apresentados os resultados da pesquisa, seguida das considerações finais.

\section{Expansão capitalista na Amazônia e a construção da Hidrelétrica de Belo Monte}

A formação socioeconômica da Amazônia brasileira caracterizou-se por um modelo colonizador de caráter extrativista, como nos demais países da América Latina, cuja vocação deveria ser servil aos países capitalistas cêntricos (GALEANO, 2013). O Estado burguês vem historicamente reproduzindo tal modelo, que se materializa por meio de ações institucionalizadas - criação de órgãos, legislação, portos, aeroportos, rodovias - cuja logística serve para consolidar a infraestrutura física e social para o capital no território (POULANTZAS, 1985). Sobre a particularidade amazônica brasileira, destaca-se a implementação dos grandes projetos, os quais são subsidiados pelo Estado brasileiro em suas três esferas de poder. Esses enclaves transmutados de grandes projetos econômicos estão em várias áreas: mineração, siderurgia, construção de hidrelétricas e de grandes indústrias; fábricas especializadas na extração de produtos primários, com baixa tecnologia, cujos produtos originam as commodities, fundamentais à dinâmica colonizadora de usurpação na região, que mobiliza lucros - essenciais ao modelo capitalista de produção. Nesse contexto, destaca-se a posição estratégica da Amazônia Paraense no cenário mundial, com elementos materiais para a reprodução e a acumulação do capital, cujos componentes, natureza e mão de obra são abundantes e expõem o território às reiteradas ofensivas do capital. Os programas e os projetos firmados pelo Estado burguês, aguçam os conflitos e as desigualdades sociais que, dialeticamente, provocam o contraponto dos grupos sociais orgânicos nessa territorialidade. 
Frutos da sociedade civil, os movimentos sociais consistem em processos organizativos cujos agentes são sujeitos determinantes para as bases da sociedade política (Estado). Desse modo, o conceito de movimentos sociais encontra-se em permanente construção, por isso é histórico. Nesse campo, destaca-se a luta social, que diz respeito às ações motivadas por conflitos, injustiças, perdas ou conquistas e que devem ser analisadas em um contexto histórico e social. Outro elemento teórico destacado no contexto das lutas na Amazônia é a questão da resistência. Essa se volta contra algo externo que ameaça, viola, e que vai contra um sistema organizacional peculiar (GOHN, 2000).

Segundo os dados do censo de 2010, do IBGE, Altamira, sendo o maior município da Região, possuía até o referido ano cerca de 100 mil habitantes. Com a instalação da UHEBM, mais 96.000 pessoas se deslocaram para os municípios de Altamira e Vitória do Xingu, o que duplicou o número de habitantes em detrimento de uma infraestrutura já deficitária (MELO, 2016). Sendo um empreendimento de aproveitamento hidrelétrico caracterizado pela produção e geração de energia, a UHEBM teve, em princípio, o consórcio Norte Energia como o ganhador do leilão ocorrido em 2010 e, em um segundo momento, sofreu modificação nas empresas do consórcio. Em função das exigências normativas, foi necessária a criação de uma Sociedade de Propósito Específico (SPE) para que o financiamento da obra fosse viabilizado pelo governo federal (MELO, 2016). Financiado $85 \%$ pelo fundo público brasileiro, as fontes de subsídios advêm do BNDES, das linhas de créditos via Fundo de Garantia por Tempo de Serviço (FGTS), Fundo de Amparo ao Trabalhador (FAT) e das estatais, Centrais Elétricas Brasileiras S.A (ELETROBRAS), Centrais Elétricas do Norte do Brasil S.A (ELETRONORTE) e Companhia Hidroelétrica do São Francisco (CHESF). De acordo com o relatório do Programa de Aceleração do Crescimento (PAC), referente aos anos de 2011 a 2014, a SPE apresenta as seguintes participações: "ELETRONORTE 19,98\%; ELETROBRAS 15\%; CHESF 15\%; Petros 10\%; Funcef 5\%; Amazônia (Cemig e Light) 9,77\%; Neoenergia 10\%; Vale 9\%; Sinobras 1\%; Caixa FIP Cevix 5\%; J. Malucelli Energia 0,25\%" (BRASIL, [201-], p. 106)³. Destaca-se que a margem de financiamento público a um empreendimento privado não deve ultrapassar $80 \%$. Todavia, ao analisar o montante da obra que equivale a $\mathrm{R} \$ 28,9$ bilhões, sendo 24,5 bilhões financiados pelo Governo Federal, vê-se que corresponde a aproximadamente $85 \%$ do financiamento, e ultrapassa o percentual previsto em lei. Assim, tem-se o agravante do valor total da participação dos investidores privados correspondente a aproximadamente $15,2 \%$, o qual não atende a exigência da participação privada que deve ser superior a $20 \%$ do total do investimento (CONSIÇÕES..., [201-]).

A ciranda financeira traduz a realidade do que representa o subsídio do Estado ao empreendimento, pois, de acordo com a legislação, o BNDES transgrediu o critério legal de financiamento do erário público, conforme exposto e, ao mesmo tempo permite entender porque as empresas passaram de proprietárias do empreendimento para construtoras da obra, ficando o Estado no papel de gestor e financiador principal da hidrelétrica. Essas contradições reiteram o caráter ilegal e inconstitucional do financiamento da UHEBM (MELO, 2016).

Desse modo, mesmo sendo alvo de polêmicas denunciadas em virtude do financiamento pouco transparente do BNDES, das licenças prévias ambientais e de instalações que contradizem os estudos e a legislação brasileira, o megaempreendimento seguiu com uma agenda que iniciou em $2011 \mathrm{com}$ previsão de conclusão para 2019, e, muito embora no cronograma da obra estivesse previsto o início das atividades para o ano de 2015, a UHEBM foi inaugurada parcialmente em maio de 2016, “[...] Duas turbinas já começaram a gerar energia comercialmente desde abril [...]. Juntas, adicionam 649,9 MW ao Sistema Interligado Nacional (SIN)" (BRASIL, 2016) que, após sua conclusão em 2019, passou a funcionar apenas com $30 \%$ de sua capacidade de instalação.

A UHEBM, como projeto do capital, promove níveis de destruição material e imaterial que rebatem diretamente nos povos indígenas, povos tradicionais, migrantes, trabalhadores, e, na população como um todo, considerando o desequilíbrio socioambiental provocado pela intervenção do capital sobre o homem e a natureza. Trata-se de uma racionalidade hegemônica, que traz em seu bojo modificações radicais e violentas ao modo de vida local e, por contraditório, suscita um contra movimento de resistência, por meio de ações sociopolíticas que fazem frente, guardada as devidas proporções, às pressões do modo de produção capitalista (DAVIDSON, 1978 apud SAID, 2011). Ressalte-se que essas violações não têm sido capazes de calar as multivozes dos movimentos sociais na Região Amazônica, tal como identificado na pesquisa. 


\section{Lutas sociais e resistências na área de influência da Usina Hidrelétrica de Belo Monte}

Em meados da década de 1970 foram deflagrados os estudos de viabilidade técnica e econômica para a formação de um complexo hidrelétrico na região,

voltando-se à bacia Amazônica e, mais especificamente, à sub-bacia Xingu, observa-se que o complexo hidrelétrico Kararaô, como foi inicialmente conhecido [...], teve seu início em 1975 com os estudos realizados pela Eletronorte para avaliar o aproveitamento hidrelétrico da bacia do rio, concluído em 1980. (RODRIGUES, 2012, p. 397).

O referido complexo acirrou ações e debates por parte de grupos das universidades, dos movimentos sociais e populares, segmentos da Igreja Católica por meio da Prelazia do Xingu, Conselho Indigenista Missionário (CIMI), Comissão Pastoral da Terra (CPT), movimento de trabalhadores rurais, movimento indígena, dentre outros. Desde a década de 1960 os moradores da região do Xingu já testemunhavam históricos de violência em virtude da luta por terras, trazendo à tona a ausência da reforma agrária, e do acúmulo de terras em favor dos grandes latifúndios, o desmatamento, a exploração de madeira e de minérios, contradições estas que já se faziam presentes no território que, historicamente, convive com a exploração, violência e saque.

Atrelam-se a esses processos, os impactos provocados pela construção da hidrelétrica de Tucuruí que também contribuiu para mobilização da realização do $1^{\circ}$ Encontro dos Povos Indígenas do Xingu em 1989, ato político que demarcou historicamente o enfrentamento e a resistência ao projeto hidrelétrico (RODRIGUES, 2012). Após 30 anos, o governo de coalizão do Partido do Trabalhadores (PT), decorridos a partir dos primeiros estudos efetivados pelo corpo de técnicos da autocracia militar (1975), retoma em 2005 o projeto hidrelétrico para o Xingu, que, nesse contexto, passa a ser denominado de Complexo Hidrelétrico de Belo Monte (CHEBM), e toma formato final nos governos de Dilma Rousseff (2011-2017). Em 2011 a inicia-se a execução da UHEBM sob protestos dos movimentos sociais, com forte protagonismo do movimento indígena, da academia e alguns representantes do Ministério Público - sob a suspeita de que não se tratava apenas de uma usina, e sim de um complexo hidrelétrico, envolvendo as construções de outras usinas ${ }^{4}$.

Nesse contexto político complexo, esta pesquisa demonstrou que as orientações políticas das ações dos movimentos são heterogêneas, conforme se observa na fala de um entrevistado:

Há várias concepções que norteiam as organizações. Os movimentos locais receberam forte influência do
Partido dos Trabalhadores. Mesmo em face das problemáticas, seguimos articulando debates, encontros,
reuniões com carroceiros, oleiros, conselho de segurança pública, sindicato dos urbanitários, sindicato
dos funcionários da Companhia Elétrica do Pará e Companhia de Saneamento do Pará, na tentativa de
unificar ao máximo. As articulações se fazem por meio de pautas e demandas. (Pesquisa de Campo,
Entrevistado 8. Altamira, 2014) .

Em algumas narrativas identificou-se que há grupos que, por não terem muita clareza teórica e política do que representa o projeto de acumulação do capital, que avança violentamente sobre o território, disputam espaços, sobretudo recursos, o que vem gerando rivalidades entre aqueles grupos que estabelecem articulação ou diálogo com o governo federal. Um dado preocupante que emergiu das entrevistas diz respeito à pressão sobre os povos indígenas, que ficam vulneráveis na relação assimétrica com a Norte Energia, considerando as peculiaridades da forma de organização social dos povos, sem que haja a mediação dos órgãos protetivos do Estado, como a Fundação Nacional do Índio (FUNAI), a Fundação Nacional de Saúde (FUNASA) etc., que se constitui em uma ameaça real ao etnocídio dos povos indígenas. Um dos entrevistados denunciou a incerteza do futuro dos povos indígenas mediante essa racionalidade autoritária de desenvolvimento:

As populações indígenas, e não apenas os da Volta Grande, isso eu lhe digo com toda sinceridade não vão sobreviver, como povos não vão sobreviver, fisicamente podem sobreviver, mas por que já estamos vendo aqui uma família indígena ou uma comunidade indígena vivem de quê? Da pesca, da caça, da agricultura familiar, tem seu estilo e eles são arrancados daqui e tão onde? Tão na periferia e ainda recebem dinheiro, que eu tenho nada contra, que o pobre ainda vai me dizer que até agora nunca receberam nada e agora que nós estamos recebendo dinheiro que tu faz com o dinheiro? Cada caso de embriaguez e alcoolismo. [...] 
Quem os fez tais? Essa é a pergunta. E aí eles não têm profissão, talvez mais tarde pode pegar uma vaga de ajudante de pedreiro ou qualquer outra coisa [...]. (Pesquisa de Campo, Entrevistado 06. Altamira, 2014).

Já os grupos, com melhor clareza dessa relação contraditória, que impõem um desenvolvimento conservador para o território, defendem uma posição política radical à construção da UHEBM. Desse modo, as concepções diferenciadas contribuem para divisões na base dos movimentos sociais, mas não anulam a continuidade da luta. Em relação à variável Níveis de pressão e ameaças sofridas pelos movimentos, identificou-se as formas coercitivas que ameaçam as forças de resistência, materializadas pelos registros de violência, sobretudo, envolvendo a execução de lideranças na região, como o assassinato em 2001, em Altamira, de Ademir A. Federicci, conhecido como Dema, que coordenava o Movimento pelo Desenvolvimento da Transamazônica e Xingu (MDTX) que combatia o projeto da UHEBM; o homicídio da religiosa estadunidense Dorothy Stang, em 2005, no município de Anapu, e, em 2011, o duplo assassinato do casal extrativista Maria do Espírito Santo e José Cláudio Ribeiro, no município de Nova Ipixuna, que lutavam contra a invasão dos madeireiros e pelo direito à terra. Estes foram assassinados por lutarem em favor da justiça ambiental e contra o modelo de desenvolvimento capitalista: "Os assassinatos mancham de sangue a geografia do estado. Mortos em diferentes pontos do mapa, Ademir, Dorothy, Maria e José Cláudio retratam a trajetória de homens e mulheres contidos à bala na luta por justiça ambiental no Pará”. (OTTERLOO et al., 2014, p. 21, grifo do autor).

Nas entrevistas houve a denúncia da existência de um grupo de extermínio, denominado consórcio da morte, no qual a vida das pessoas é precificada e tabelada de acordo com o nível de importância e liderança que exercem no movimento. Nesse solo fértil de impunidades e violências, a UHEBM veio acirrar ainda mais tais conflitos, em que é recorrente a criminalização dos movimentos por meio de assédio moral e psicológico; ações judiciais impetradas ao movimento, demissões, retaliações, perseguições, grampos telefônicos, espionagem e ameaça de morte, configurando um quadro de autoritarismo e violação de direitos, ainda que em um contexto concebido como democrático.

Os relatos denunciaram segmentos do poder público, nas esferas federal, estadual e municipal, que incorreram em violações. Somam-se, ainda, os entes privados, a Norte Energia S/A (Nesa), o Consórcio Construtor Belo Monte (CCBM), mídia local, fazendeiros e posseiros, revelando a leniência e o caráter repressivo e coercitivo do Estado. Se antes da UHEBM as ameaças e as violações advinham de grupos e consórcio de matadores, agora o Estado passa a ser também o violador de direitos dos movimentos sociais por meio dos aparatos de repressão, como: Polícia Militar do estado, Força Nacional, pela abertura de inquéritos judiciais, dentre outros. Como o Estado não é um bloco homogêneo, destacam-se as forças de contraponto com as ações de órgãos protetivos, como Ministério Público Federal (MPF), FUNAI, Defensoria Pública do Estado do Pará, e entidades da sociedade civil, como a Sociedade Paraense de Direitos Humanos (SPDH) e o Sindicato de educação, que agem na ativação de direitos dos movimentos sociais de resistência.

Em relação às parcerias e cooperações, se dão nos campos institucionais e não institucionais, em que prevalecem o diálogo, o acesso à informação, às políticas públicas e programas, e também no estabelecimento de ações conjuntas e partilhadas na busca por objetivos comuns, o que não significa dizer que não haja contradições e interesses antagônicos em tais relações. Entre os órgãos do poder público e dos movimentos sociais, foram observados que não se trata de relações pacíficas, há tensões, contudo, há o espaço para o diálogo. Há prevalência de parcerias e cooperações com órgãos considerados pelo movimento como mais autônomos, como o Ministério Público Federal em Altamira, e a Defensoria Pública do Estado.

Quanto ao acesso ao poder municipal, há respostas pertinentes às prefeituras dos três municípios visitados, Altamira, Vitória do Xingu e Senador José Porfírio, considerando que os segmentos transitam em toda a região $\mathrm{e}$, articulam parcerias nos municípios impactados pela UHEBM. Em virtude dessa especificidade, unificaram-se as respostas de que mais de 63\% estabelecem parceria com a Câmara municipal, 25\% estabelecem parcerias com o poder executivo municipal e $6 \%$ respectivamente, correspondem às secretarias dos três municípios, citou-se com mais frequência a Secretaria de Meio Ambiente.

A pesquisa identificou também que as entidades realizam parcerias e cooperações com organizações locais nacionais, tais como: Associações de professores e de Moradores, Cooperativas, Conselhos de Classe, Pastorais sociais, Confederações, Centrais sindicais, Sindicatos, Igrejas, Instituições de Ensino Superior, ONGs, Movimentos Populares, Organização da Sociedade Civil de Interesse Público, Partidos políticos, Rádios comunitárias, SPDH, Serviço Social da Indústria (SESI), etc. O desenho plural e diversificado dos níveis e 
escalas de parcerias e cooperações que ocorrem nas esferas locais dos municípios demonstra articulações em níveis nacionais e transnacionais, citam-se articulações e parcerias com embaixadas, ONGs internacionais, União Europeia, Programa das Nações Unidas para o Desenvolvimento (PNUD). Essa miríade de articulações revela que essas forças sociais são dinâmicas, têm fluidez, alcance e percepção de como ativar mecanismos de parcerias e cooperações que venham a ser somadas às suas lutas sociais ${ }^{6}$. A pesquisa revela o intercâmbio entre os grupos e forças sociais, e o diálogo com o poder público, que ainda de forma controversa, estabelece cooperações e parcerias, ou seja, a resistência é essa articulação macro e micro que estrutura as lutas sociais, com pluralidade de vozes, visões e ideologias. Tais forças conseguem articular debates ampliados, e, em razão de sua diversidade e de contradições, contribui para consolidar o espaço democrático da construção dessas forças.

Todavia, os movimentos sociais incorrem em um limite objetivo, que diz respeito à autossustentabilidade que se constitui um constante desafio, considerando que cerca de 33\% captam recursos via contribuições e doações de associados. São valores incipientes que pouco viabilizam a edificação de ações constantes e sistemáticas, o que vulnerabiliza as ações e as práticas políticas. Cerca de $17 \%$ captam recursos via projetos que são as ONGs, que conseguem desenvolver ações mais sistematizadas, com equipe técnica, o que possibilita uma melhor efetividade nos trabalhos. De modo geral, os movimentos sociais apresentam uma restrita autonomia financeira, o que exige destes criatividade e cooperação no desenvolvimento de suas ações coletivas, e 33\% se mantêm por meio da agricultura familiar de subsistência.

Tendo em vista a questão dos recursos, destaca-se o Comitê Gestor do Plano de Desenvolvimento Regional Sustentável do Xingu (PDRSX). Com um formato paritário, é composto por representantes da sociedade civil, do governo e do mercado. Nesse Comitê, concentram-se a gestão, o planejamento de programas e projetos, as metas e a deliberação dos recursos para atender ações de mitigação e compensação dos impactos da hidrelétrica. Destaca-se que 60\% dos segmentos entrevistados não estão vinculados ao PDRSX (BRASIL, 2012). Os entrevistados foram unânimes em afirmar que se trata de um espaço de disputa de poder e beneficiamento, cuja metodologia não propicia uma participação equitativa, e que as ações deliberadas, os recursos e os projetos pouco atendem às demandas coletivas, uma vez que prevalecem interesses individuais acirrados por disputas. Entende-se que é um espaço de assimetria de poderes, que retira o foco dos impactos que a UHEBM provoca, além de acirrar disputas por recursos financeiros, contribuindo para cindir os grupos, fragilizar o diálogo e o intercâmbio entre os representantes dos municípios afetados.

Na questão da participação e articulação nos espaços de poder institucional e não institucionalizados, os elementos de análise sobre os avanços e os retrocessos das lutas sociais e de resistência dos movimentos são importantes para avaliar a totalidade. Observa-se um movimento de forças que se articulam e criam formas próprias de organização com base em demandas específicas e coletivas. Os avanços corroboram a luta por políticas públicas, como o Programa Luz para Todos, habitação, legalização e demarcação das terras indígenas, alfabetização, ou seja, seguem na luta por direitos sociais. Essa visibilidade contribui para pautar, e agendar publicamente as questões relacionadas às políticas públicas e à responsabilização pelas violações dos direitos.

Os aspectos avaliativos da trajetória das lutas sociais encampadas apontam os retrocessos e desafios, cujas narrativas dos entrevistados enaltecem a permanente luta pelo direito à moradia, denunciando que os assentamentos criados em função da construção da UHEBM, que desterritorializou moradores de Altamira e de Vitória do Xingu, tenham equipamentos públicos, como postos de saúde, escolas, transporte público, mercados, espaços coletivos de convivência, lazer. Neste foi destacado a forma compulsória de desapropriação, por conseguinte, de toda uma história construída alicerçada pelos laços de vizinhança e solidariedade. Ainda sobre os retrocessos, destaca-se a falta de transparência, por parte da Nesa e do poder público, em relação a dimensão dos impactos reais causados pela UHEBM. O que se prevê, e já se vivencia são as ameaças da extinção de culturas tradicionais de ribeirinhos, pescadores artesanais, indígenas; a extinção de postos de trabalho, a exemplo dos pescadores. Esses fatores, ativam as ações políticas envidadas pelos movimentos que sentem a pressão constante materializada pela criminalização, pela cooptação, que forjam fragmentações nos grupos sociais. Todavia, isso não engessou as lutas sociais, que são representadas por uma pluralidade, as quais tensionadas por essa diversidade, qualificam o movimento na direção da ampliação e da construção de uma base mais democrática, que efervesce numa dinâmica contraditória da luta entre capital e trabalho.

Nessa direção, os desafios que se colocam servem também para apontar o norte dessas lutas e resistências, que seguem ativando ações políticas, como manifestações, paralisações, ocupações, mobilizações, participações em conferências, seminários nacionais e internacionais, publicações gráficas e nas mídias sociais, participações 
em audiências públicas, projetos, reuniões com câmaras e setores do poder público, com vistas a denunciar as violações e pautar internacionalmente a questão. O depoimento emblemático de uma entrevistada ilustra as várias escalas de articulações e visibilidade:

Eu passei agora 15 dias em janeiro de 2014 na Europa bancada por várias ONGs, inclusive alguns cineastas da Alemanha, de Munique, Stuttgart e Ulm. Falei para os cineastas e vários intelectuais, alunos, acadêmicos, jornalistas perguntavam, mas o que é mesmo que você quer dizer para os europeus? [...] Quero dizer para os homens e mulheres da Europa, principalmente aqueles que constituíram patrimônios faraônicos a custas do sangue dos latinos, lá da minha América, que em alguns países da América Latina não têm mais indígenas porque acabaram tudo. Lá na minha terra no Xingu ainda tem os Xipaias, os Jurunas, os Xicrins e tem os quilombolas, pescadores, as mulheres e os homens eu vim aqui em nome desse movimento dizer pra vocês e para os grandes patrimônios do capital alemão não fabricarem mais turbinas pra vender aos países latinos, pra barganhar com os governos conservadores, que nós temos lá, que são todos neoliberais, capitalistas aliados as corrupções e não se importam com a vida da gente. Vim dizer pra vocês que já dormem em berço esplêndido que vocês não fiquem eternamente em berço esplêndido, por causa da produção tecnológica industrial de vocês, nós estamos morrendo, eu vim pra cá dizer que Belo Monte comprou carradas e carradas de turbinas [...] lá pra fazer a barragem que tá matando nosso povo. (Pesquisa de Campo, Entrevistado 10. Altamira, 2014).

O traçado dessas lutas se dá por questões pontuais, emergenciais, a exemplo da legalização de associações, tendo em vista a necessidade dos movimentos sociais organizados só poderem acessar determinados projetos, programas e políticas quando são instituídos legalmente, respondendo a exigências como estarem inscritos no Cadastro Nacional de Pessoa Jurídica (CNPJ). Tais requisitos burocráticos são impostos até para os grupos indígenas, cuja organização social difere em muito dessa racionalidade e, que, defendem a preservação da forma social de organização de seus povos, não obstante terem seus territórios atravessados pela racionalidade capitalista (barragens, garimpos, plantação de soja, exploração de madeira etc.). Em outra escala, têm-se a luta por direitos sociais mais amplos, como alfabetização, proteção ambiental, autonomia e soberania dos povos.

Infere-se, dessa realidade, que as lutas encampadas são dinamizadas com base em demandas específicas pontuais, emergenciais, que mantêm conectividade com demandas e lutas históricas mais amplas que dizem respeito à incessante luta por direitos e cidadania, estes aqui entendidos, considerando a acepção de Coutinho (2008), como a capacidade dos sujeitos de apropriação coletiva do que é socialmente produzido, tendo em vista as necessidades humanas materiais e espirituais historicamente determinadas, mas que não apontam nesse horizonte outros projetos de sociedade - à exceção dos povos indígenas ${ }^{7}$-, embora o diálogo abaixo lance luz a uma perspectiva em construção:

[...] nós pagamos energia mais cara do mundo. [...] Somos trabalhadores(as) de baixa renda, assalariados de 1 a 3 salários mínimos, embora o governo diz que nós estamos na classe média, mas isso é pra enganar. [...] pra gente tem um efeito muito controverso, esse modelo de energia aqui pra região é um modelo ultrapassado e pra finalizar nós temos várias universidades aqui na Amazônia. Se a Amazônia é o celeiro do patrimônio que serve para o mercado internacional ele tem que servir pro mercado de pesquisa de tecnologias que venha inserir a população nesse contexto, a qualidade de vida no desenvolvimento econômico sustentável pela e para Amazônia. Então nós queremos que as instituições de estudos e pesquisa elas venham garantir esse investimento. E inserir projetos alternativos [...] querem experimentar um projeto de energia nas casas populares que estão sendo construídas nas aldeias indígenas, nos territórios quilombolas, nas comunidades de dentro da floresta, no ribeirinho nas populações das águas a gente quer esse estudo, esse experimento, quer ver outras alternativas e essa é a hora, mesmo com Belo Monte em fase de conclusão, nós vamos continuar dizendo que é possível outra invenção. (Pesquisa de Campo, Entrevistado 10. Altamira, 2014).

Depreende-se a pluralidade dos movimentos, elos de unidades em que pese a concepção do empreendimento energético para a Região do Xingu. Para estes, trata-se de um desenvolvimento exógeno que não considera a soberania, autonomia e igualdade social, por isso, segue num ciclo de violação contínua, representado pelos enclaves econômicos no território. Portanto, para os movimentos sociais, a UHEBM representa um modelo energético caro, ultrapassado e perverso do ponto de vista socioambiental. E nesse campo de lutas, as forças sociais são estruturantes e orgânicas, pois vão forjando dialeticamente o exercício de uma consciência crítica 
da sociedade sobre esse tipo de desenvolvimento econômico autoritário. O campo político e ideológico dos movimentos sociais é multifacetado, cujas diferenças e divergências contribuem para construir democraticamente as condições objetivas de desconstrução do tipo de desenvolvimento que coloca em xeque a humanidade genérica, uma vez que os danos socioambientais na Amazônia influenciam a biodiversidade planetária.

\section{Considerações finais}

A matriz energética brasileira concebe a Amazônia como uma província de geração de megawatts com vistas ao abastecimento das indústrias eletrointensivas, mineradoras, agroindústria, metalúrgica e as grandes metrópoles brasileiras e fronteiriças. Essa política reforça o caráter conservador do modelo de desenvolvimento praticado pelo Estado, numa perspectiva neoliberal que transforma água em megawatts, mercadoria preciosa no contexto da expansão da acumulação do capital sobre os elementos da natureza, e sobre os povos. As contradições oriundas da relação capital e trabalho explicitam que as lutas sociais vivenciadas na Amazônia Paraense fazem o contraponto e resistência, protagonizada por múltiplos sujeitos, como trabalhadores formais, informais, indígenas, quilombolas, ribeirinhos, extrativistas, colonos, garimpeiros artesanais, agricultores, pescadores, pesquisadores (brasileiros e estrangeiros), os quais exprimem posições que demarcam as resistências $\mathrm{e}$ as lutas sociais.

A força e a pressão que o capital exerce sobre o território contribuem para que as lutas sociais e resistências não se deem diretamente no campo da radicalização do sistema capitalista, uma vez que não se identificou na base dos movimentos sociais um projeto claro de um outro modelo societário, com exceção das formas de organização social dos povos indígenas. Todavia, a contra hegemonia que as formas sociais organizativas dos povos tradicionais praticam, expressam outras racionalidades civilizatórias, como a economia de subsistência, a agricultura familiar, a partilha na produção, os atos de solidariedade entre as comunidades etc. É necessário trazer à luz essas experiências que se dão na territorialidade Amazônica, com vistas a um devir histórico e coletivamente construído. Neste horizonte, pode-se afirmar que a luta social dos movimentos de resistência é estruturante, tendo em vista que se combate proeminentemente a construção da UHEBM, mas para além dessa, essas forças mobilizam, articulam e se rebelam contra o que o projeto autocrático energético representa de conservador e de um desenvolvimento econômico capitalista, que nega os direitos sociais e não respeita as relações socioambientais historicamente firmadas na territorialidade pelos povos da Amazônia.

Nesse campo, as forças sociais expressam-se por meio dos movimentos sociais de resistência, que apresentam um desenho social complexo e multifacetado, cujas diferenças são saudáveis e importantes para o exercício da construção democrática e a desconstrução dos discursos ideológicos do Estado capitalista de "soberania energética" e de "energia limpa". As mediações ativadas pelas lutas sociais e resistência não cessam a problemática, mas forjam o agendamento público da questão, denunciando para a sociedade que o projeto energético brasileiro, que representa uma das facetas de mundialização do capital sobre os territórios, ameaça a humanidade genérica.

\section{Referências}

AGÊNCIA NACIONAL DE ENERGIA ELÉTRICA (ANEEL). Brasil alcança 170 mil megawatts de capacidade instalada em 2019. Assessoria Institucional da Diretoria (AID). Brasília, 30 jan. 2020. Disponível: http://bit.ly/35IP2Vo. Acesso em: 20 abr. 2020.

ARNOLD Schwarzenegger visita o Pará com James Cameron. Globo G1, São Paulo, 23 mar. 2011. Disponível em: http://glo.bo/ hVMhyw. Acesso em: 23 maio 2020.

BRASIL. Dilma inaugura Usina Hidrelétrica de Belo Monte. Brasília, DF: Ministério do Planejamento, Portal Brasil, 5 maio 2016. Disponível em: http://pac.gov.br/noticia/7be96908. Acesso em: 5 jun. 2016.

BRASIL. Pac 2, ano 1, $3^{\circ}$ Balanço 2011/2014. Brasília, DF: Ministério do Planejamento, 2012. Disponível em: http://pac.gov.br/pub/ up/relatorio/9c1d00894e901bed0a319fd797668ae3.pdf. Acesso em: 29 jun. 2020.

BRASIL. Pac 2: a gente faz um Brasil de oportunidades: 11 Balanço 2011 a 2014. Brasília, DF: Ministério do Planejamento, [201-]. Disponível em: http://pac.gov.br/pub/up/relatorio/f9d3db229b483b35923b338906b022ce.pdf. Acesso em: 29 jun. 2020. 
CONSIÇÕES de apoio à implantação do Aproveitamento Hidrelétrico Belo Monte. Rio de Janeiro, Banco Nacional de Desenvolvimento Econômico E Social, [201-]. Disponível em: https://www.bndes.gov.br/wps/portal/site/home/financiamento/produto/leiloes-infraestrutura/ belo-monte. Acesso em: 29 jun. 2020.

CONSÓRCIO CONSTRUTOR BELO MONTE (CCBM). O Consórcio. Ano 2016. Disponível em: https://www.consorciobelomonte. com.br/Publico.aspx?id=2. Acesso: 07 julh. 2016.

COUTINHO, C. N. Contra a corrente: ensaios sobre democracia e socialismo. São Paulo: Cortez, 2008.

CRUZ, R. Sting e Raoni se unem contra a Hidrelétrica de Belo Monte. Jornal Estadão, São Paulo, 22 nov. 2009. Disponível em: http:// economia.estadao.com.br/noticias/geral,sting-e-raoni-se-unem-contra-a-hidreletrica-de-belo-monte,470431. Acesso em: 22 maio 2015. GALEANO, E. As veias abertas da América Latina. Porto Alegre: L\&PM, 2013.

GOHN, M. da G. Teoria dos movimentos sociais: paradigmas clássicos e contemporâneos. São Paulo: Loyola, 2000.

HARVEY, D. A produção capitalista do espaço. São Paulo: Annablume, 2005.

INSTITUTO SOCIOAMBIENTAL (ISA). Disponível em: https://www.socioambiental.org/pt-br. Acesso em: 29 set. 2020.

INSTITUTO SOCIOAMBIENTAL (ISA). 2010. Disponível no site do Instituto Socioambiental, publicado em 2010: http://www. socioambiental.org/esp/bm/loc.asp.Março/2010. Acesso: 02 set. 2014.

MELO, K. M. dos S. Lutas sociais e resistências na área de influência da Usina de Belo Monte: a Amazônia no cenário da mundialização do capital. 2016. 268f. Tese (Doutorado em Política Social) - Departamento de Serviço Social, Universidade de Brasília, 2016.

OTTERLOO, M. H. A. et al. Somos a floresta: Cenários e narrativas de justiça ambiental na Amazônia. Fundo Dema, Belém/PA, set. 2014. Disponível em: https://fase.org.br/wp-content/uploads/2014/10/RevistaFundoDemaSomosAfloresta_ISSUU med18Set2014. pdf. Acesso em: 23 maio 2020.

PAULO NETTO, J. Introdução ao estudo do método de Marx. São Paulo: Expressão Popular, 2011.

POULANTZAS, N. O Estado, o poder, o socialismo. Rio de Janeiro: Graal, 1985.

RODRIGUES, E. B. Território e soberania na globalização: Amazônia, jardim de águas sedento. Belo Horizonte: Fórum, 2012.

SAID, E. W. Cultura e imperialismo. São Paulo: Companhia das Letras, 2011.

UMA GOTA no Oceano. “É a Gota D’Agua + 10”. 2011. (5m7s). Disponível: https://www.youtube.com/watch?v=DIpAbXsWH7U. Acesso em: 15 jun. 2014.

\section{Notas}

1 Os municípios que estão na área de influência da Hidrelétrica são: Vitória do Xingu (onde localiza-se a UHEBM), Altamira, Brasil Novo, Anapu, Senador José Porfírio, Porto de Moz, Medicilândia, Gurupá, Placas, Uruará e Pacajá, além de dez territórios indígenas e vinte e uma comunidades quilombolas. (INSTITUTO SOCIOAMBIENTAL, 2010).

2 As instituições e representações contatadas para as entrevistas foram: Movimento Xingu Vivo para Sempre (MXVPS), Movimento dos Atingidos por Barragens (MAB), Instituto Socioambiental (ISA), Conselho Indigenista Missionário (CIMI), Prelazia do Xingu, Sindicato dos Trabalhadores em Educação de Altamira (SINTEP), Colônia de Pescadores Zona 57 (Z-57) de Altamira, Colônia de Pescadores Zona 70 (Z-70) de Senador José Porfírio, Representante da Associação de Bairro e da Colônia de Pescadores, Rádio Comunitária de Vitória do Xingu, Associação Organizada de Moradores de Vitória do Xingu (AMOVIX), Organização dos Habitantes do Município de Vitória do Xingu, Movimentos de Mulheres do Campo e Cidade de Vitória de Xingu (MMCCVX), Associação de Mulheres Urbanas e Rurais (AMUR) de Senador José Porfírio, Liderança Indígena da Aldeia Paquiçamba e Representante Indígena da Aldeia Boa Vista, ambas localizadas no município de Vitória do Xingu.

3 Para a realização da construção da UHEBM, a Norte Energia contratou o Consórcio Construtora Belo Monte (CCBM), composto por dez empresas privadas, com os seguintes percentuais de acionários: Andrade Gutierrez 18\%; N. Odebrecht 16\%; Camargo Corrêa 16\%; Queiroz Galvão 11,50\%; OAS 11,50\%; Contern 10\%; Galvão 10\%; Serveng 3\%; J. Malucelli 2\% e Cetenco $2 \%$ (CONSÓRCIO CONSTRUTOR BELO MONTE, 2016).

4 Ressalte-se a vinculação da UHEBM à influência da Iniciativa para a Integração da Infraestrutura Regional Sul-Americana (IIRSA), consolidada em 2007, cujo eixo energético assume uma importância central na política governamental brasileira, capitaneada pelo Programa de Aceleração do Crescimento (PAC). A lógica que norteia a política energética brasileira, por princípio, não considera o modo de vida e a organização social dos povos da Amazônia, o que provocou polêmicas por se tratar de uma forma de desenvolvimento predatória e conservadora, contrária à perspectiva ideológica defendida pelo governo brasileiro de coalizão do PT, cujo discurso era pautado pela defesa dos direitos sociais e da democracia, mas que na prática, retoma e implementa arbitrariamente um projeto do governo militar.

$5 \quad$ Nas entrevistas foram mantidas as grafias originais conforme fontes consultadas. 
6 Frutos dessas articulações de parceria e cooperação citam-se as visitas em Altamira do cineasta James Cameron e do ator Arnold Schwarzenegger (ARNOLD..., 2011); do músico e ativista Sting (CRUZ, 2009); de artistas de renome nacional que gravaram vídeos intitulados movimento Gota da Água, de apoio às lutas em defesa dos povos da Amazônia (UMA GOTA..., 2011). Essas parcerias contribuíram para dar visibilidade ao mundo dos impactos da Usina Hidrelétrica de Belo Monte na Região do médio Xingu.

7 Não é possível analisar os povos indígenas de forma homogênea, todavia, a sociabilidade desses povos originários perpassa por uma relação em que há uma convivência equilibrada entre os recursos naturais advindos das matas, das águas, da terra, do ar, numa perspectiva de subsistência com vistas a reprodução de seus modos de vida. Na forma de organização social dos povos indígenas, observa-se um profundo respeito às questões materiais e imateriais e às ancestralidades. Do ponto de vista do território, as terras indígenas, de regra, localizam-se em espaço estratégicos para a instalação e exploração do grande capital promovido por meio dos grandes projetos de produção de energia, de mineração, do agronegócio etc., rebatendo diretamente nos povos indígenas na medida em que sofrem a pressão e os impactos das ações violentas de madeireiros, garimpeiros, sojeiros, pecuaristas, e no caso específico de Belo Monte, do próprio Estado. Assim, o desenho complexo do território amazônico é solo fértil em riquezas materiais e imateriais à medida que ocorrem contraditoriamente, a agudização da pobreza e violação de seus povos.

\section{Kátia Maria dos Santos Melo}

katiasmel1@gmail.com

Doutorado em Política Social pela Universidade de Brasília (UnB)

Professora da graduação e do Programa de Pós-Graduação Profissional em Educação Escolar Indígena da Universidade do Estado do Pará (UEPA)

\section{UEPA}

Travessa Djalma Dutra, s/n - Telégrafo.

Belém - Pará - Brasil

CEP: 66113-010

\section{Agradecimentos}

Este artigo é fruto de minha Tese de doutorado cuja trajetória contou com a colaboração e solidariedade de muitos sujeitos os quais registro a minha gratidão: aos Povos da Amazônia, a cada homem, a cada mulher, a cada jovem, a cada criança do Xingu por não desistirem de seus sonhos, de seus saberes, dizeres, modo de ser e viver e que frente a adversidade não fogem à luta. Seguem como a correnteza do Rio Xingu, mesmo quando o caminho não lhes é favorável. A resistência desses homens e mulheres nutre a esperança da luta social no sentido de que jamais devemos nos apequenar e sim lutar as nossas lutas, na direção do exercício da solidariedade, das práticas sociais baseadas na fraternidade, da convivência civilizatória entre o homem e a natureza. Registro ainda minha gratidão as pessoas que por meio de suas experiências e ensinamentos renovam a esperança no coletivo e que tem muito a nos ensinar: a minha orientadora, $\operatorname{Prof}^{\mathrm{a}} \operatorname{Dr}^{\mathrm{a}}$. Maria Lúcia Pinto Leal; Prof ${ }^{\mathrm{a}}$ Dr $^{a}$ Joana Valente Santana, Prof ${ }^{a}$. Ms. Joaquina Barata Teixeira, Aldebaran Moura (In memoriam), Marcos Mota, Fernando Monteiro, Artur Melo e Deodata Santos.

Agência financiadora

Não se aplica.

Contribuições das autoras

Não se aplica.

Aprovação por Comitê de Ética e consentimento para participação

Não se aplica.

Consentimento para publicação

Consentimento da Autora.

Conflito de interesses

Não há conflito de interesses. 